\title{
The implications of Brexit for the Irish health system
}

\author{
Brian Turner ${ }^{1}$
}

Received: 26 June 2020 / Accepted: 31 August 2020 / Published online: 8 September 2020

(C) Royal Academy of Medicine in Ireland 2020

While COVID-19 has rightly been the focus of attention in recent times, the previous issue of concern in IrelandBrexit - has not gone away. Although the UK signed up to a transitional arrangement, if a trade deal is not concluded by the end of 2020, then it will essentially mean a hard Brexit by another name. This will have significant effects on the Irish health system, which will be manifested in several ways.

Issue
Medicines
Cross-border car
Recognition of
qualifications
qualifications

Economic impact

\section{Effect}

Some measures have been put in place to avoid shortages, although it remains to be seen how effective these would be in practice [1].

Assurances have been given regarding the continued right of Irish and UK citizens to receive treatment in the other jurisdiction and to cross-border healthcare services, which are covered by service level agreements [1].

There may be delays to the recognition of UK qualifications in Ireland (for those whose qualifications are not already recognised here), as these would have to be applied for as would any qualifications from outside the EU [1].

\section{Brexit will further weaken the Irish economy, addition to the COVID-related shock. This will impact both the Government, through lower tax revenue, and individuals, through higher unemployment and lower disposable income [2] as well as higher prices for some imported goods [3], which will have knock-on implications on a number of areas of the health system, as discussed below. \\ Health service funding The additional negative shock to the Irish economy of Brexit will further reduce Government revenue, through lower taxes, and increase Government spending,}

Brian Turner

b.turner@ucc.ie

1 Department of Economics, Cork University Business School, University College Cork, Cork, Ireland (continued)

particularly on those sectors that are most adversely affected by Brexit, such as agri-food. This may have implications on the available funding for spending on areas such as health.

Recruitment and retention of staff

Implementation of Sláintecare

Private health insurance

Access to care
The anticipated exit of some medical personnel from the UK due to Brexit [4] might help with the recruitment of additional staff envisaged under Sláintecare [5], which calls for an additional 593 public hospital consultants, and the Health Service Capacity Review [6], which calls for a $48 \%$ increase in the primary care workforce. However, Ireland is competing internationally for medical workforce, with anticipated shortages of doctors and nurses at an OECD level in 2030, including in a number of countries to which Irish medical and nursing graduates are attracted to work [7].

Sláintecare envisages an additional $€ 2.9$ bn per annum spending on health by the end of the plan, over and above the increases arising from demographic factors and medical inflation, for which the report allows three percent per annum of an increase in spending. It also envisages a $€ 3$ bn transition fund over the first 6 years of the plan's lifetime [5]. The economic impact of Brexit could jeopardise the availability of funding for health, in turn adversely affecting the roll-out of the Sláintecare reforms.

The economic impacts are also likely to affect take-up of private health insurance, which is currently $46 \%$ of the population [8]. While Sláintecare envisages a reduction in take-up due to improvements in the public health system [5], such a reduction in the absence of this would lead to more people relying on the public system, putting pressure on already stretched resources.

Worsening economic conditions could also affect the ability of some people to afford care, particularly if the roll-out of universal GP care, envisaged under Sláintecare, is delayed. Ireland is unusual in not having universal primary care entitlements and there is evidence that some people defer seeking care due to cost [9]. 
Therefore, while certain aspects of Irish-UK co-operation in the health arena would continue post-Brexit, given the Common Travel Area, much-needed and overdue investment in the Irish health system - which has historically been underfunded [10] - is likely to suffer. This could hamstring the current reform agenda, while a deterioration in macroeconomic conditions, particularly wages and unemployment, could have adverse consequences for some people's access to both public and private health services. This should be of concern to Irish health policy-makers and residents alike.

Author's contributions Sole author, responsible for the article in its entirety

Data availability N/A

\section{Compliance with ethical standards}

Conflict of interest N/A

Code availability N/A

\section{References}

1. Department of Health (2019) Brexit Contingency and Preparedness Update. Available at https://health.gov.ie/brexit-contingency-andpreparedness-update/. Accessed 20 August 2020
2. Bergin A, Economides P, Garcia-Rodriguez A, Murphy G (2019) Ireland and Brexit: modelling the impact of deal and no-deal scenarios. Economic and Social Research Institute, Dublin

3. Social Justice Ireland (2020) The dangers of Brexit have not gone away. Available at https://www.socialjustice.ie/content/policyissues/dangers-brexit-have-not-gone-away. Accessed 21 August 2020

4. van Schalkwyk M, Barlow P, Stuckler D, Rae M, Lang T, Hervey T, McKee M (2019) Assessing the health effects of a "no deal" Brexit. BMJ 366:I5300

5. Committee on the Future of Healthcare (2017) Sláintecare Report. Government of Ireland, Dublin

6. PA Consulting (2018) Health Service Capacity Review 2018. Department of Health, Dublin

7. Scheffler R, Arnold D (2019) Projecting shortages and surpluses of doctors and nurses in the OECD: what looms ahead. Health Econ Policy Law 14(2):274-290

8. Health Insurance Authority (2020) Market Figures, March 2020. The Health Insurance Authority, Dublin Available at https://www. hia.ie/publication/market-statistics. Accessed 20 August 2020

9. O'Reilly D, O'Dowd T, Galway K et al (2007) Consultation charges in Ireland deter a large proportion of patients from seeing the GP: Results of a cross-sectional survey. Eur J Gen Pract 13(4): 231-236

10. Turner B (2018) Putting Ireland's health spending into perspective. Lancet 391:833-834

Publisher's note Springer Nature remains neutral with regard to jurisdictional claims in published maps and institutional affiliations. 